\title{
Sir Charles Frank Receives 1987 Von Hippel Award
}

The Materials Research Society will present its most prestigious award, the Von Hippel Award, to Sir Charles Frank at a ceremony to be held in conjunction with the 1987 MRS Fall Meeting. The award cites Sir Charles for "his wide ranging impact on modern materials science through seminal contributions in areas of inorganic crystals, metals, polymers and liquid crystals; and his outstanding research in crystallography, chemistry, physics and materials science which exemplifies the interdisciplinary approach." During his professional career spanning the last five decades, Sir Charles has had a major influence on the development of entire fields of research on diverse materials.

Sir Charles was born in South Africa in 1911. He was educated in the United Kingdom, obtaining his PhD from Oxford University in 1937. He held positions at the Kaiser Wilhelm Institut für Physik in Berlin and the Colloid Science Laboratory at Cambridge before his appointment as assistant director of intelligence (science) within the Air Ministry in 1940. After the war he joined the University of Bristol as a research fellow in the Wills Physics Laboratory. In 1954 he was appointed the Henry Overton Wills Professor in the Department of Physics which he eventually headed in 1969 until assuming professor emeritus status in 1976.

Among Sir Charles' scientific contributions are:

1. Invention of the screw dislocation mechanism of crystal growth which



Sir Charles Frank

1987 Von Hippel Award Recipient

resolved a long-standing problem, going back to Gibbs, of why polyhedral single crystals in dilute fluids grow at easily measurable rates even when departures from equilibrium are minute. The morphological and kinetic predictions derived from this theory by Frank and his collaborators have now been thoroughly confirmed by numerous experimenters.

2. Invention, also made independently and virtually simultaneously by $T$. Read, of the dislocation "mill," now known as the Frank-Read source, which leads to the internal multiplication of dislocations during plastic flow.
3. Development of the theory for why "chain folding" is the preferred mode of crystallization of linear polymers. This theory strongly influenced subsequent research of polymer crystallization morphology.

4. A more rigorous development of the Oseen curvature-elasticity theory of liquid crystals which led to a more quantitative characterization of liquid crystal structure and its response to molecular orienting forces. Frank's contribution was a major stimulus for the recent resurgence of research on liquid crystals.

5. Development, in collaboration with J. S. Kasper, of the principles of packing tetrahedra, systematically distorted, to form periodic structures which are exemplified by the so-called Frank-Kasper phases of numerous intermetallic compounds. These principles were applied by others to develop models for metallic glasses and for the recently discovered icosahedral quasiperiodic crystals.

6. Development of the theory, in collaboration with van der Merwe, for the structure and energy of misfitting monolayers on crystalline surfaces. This theory has been widely applied to the interpretation of the initial stages of thin film formation on crystalline substrates.

The MRS Awards Ceremony will be held 6:00 pm, December 2 in the Grand Ballroom of the Boston Marriott Hotel/Copley Place, after which Sir Charles will present an open lecture for attendees of the 1987 MRS Fall Meeting.

\section{$\mathrm{M} R \mathrm{RS}$}

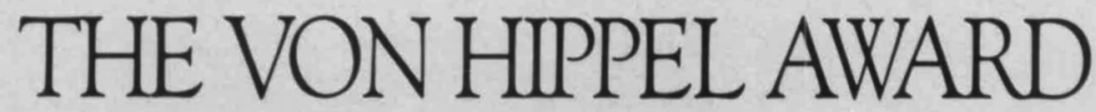

The Von Hippel Award is the Materials Research Society's most prestigious award. It is presented annually to the living scientist who, in the Society's estimation, best exemplifies throughout a career the originality, brilliance of intellect, and diligence of purpose that are the hallmark of science at its best; who adheres to the strictest ethical standards and highest code of professional integrity; and whose vision transcends conventional disciplines, as does the science of materials itself.

The award consists of a synthetic ruby crystal suitably mounted, a cash honorarium, and a lifetime membership in the Society. It is named for Arthur Robert von Hippel, emeritus professor of the Massachusetts Institute of Technology, who was also its first recipient.

The MRS Awards Committee solicits nominations annually from among the membership and elsewhere in the community of materials scientists. The nominees are evaluated against the Society's criteria, rather than against each other. From among the candidates it has reviewed, the Awards Committee puts forward the names of the principal contenders for the honor. The nominees are considered in confidence by the Council of the Society. The Council, representative of the many disciplines and institutions within MRS, makes the final decision by a majority vote. 